\title{
Factors associated with sexual violence among female administrative staff of Mekelle University, North Ethiopia
}

\author{
Sara Bahta Galu*, Haftu Berhe Gebru², Yohannes Tesfay Abebe², Kahsu Gebrekirstos Gebrekidan², \\ Atsede Fantahun Aregay ${ }^{2}$, Kidane Gebremicheal Hailu ${ }^{3}$ and Gerezgiher Buruh Abera ${ }^{2}$
}

\begin{abstract}
Objective: To assess factors associated with sexual violence among female administrative staffs of Mekelle University, North Ethiopia.

Results: From the total number of participants, 188 (52.8\%) had shift work and 110 (30.9\%) of these had day and night shift. About half 180 (50.2\%) of the participants face sexual violence similarly, 53 (14.9\%) of the victims of violence performed by their boss. In multiple logistic regression analysis young age [AOR: 2.319 (1.059-5.075)], educational status of secondary school or less [AOR: 1.981 (1.126-3.485)], office and students related workplace [AOR: 4.143 (1.975-8.687), 2.887 (1.396-5.973)], having night shift [AOR: 2.131 (1.258-3.611)], having multiple partner (AOR: 8.916 (3.052-26.047)] and knowing other female violated in office [AOR: 3.920 (2.326-6.606)] were the factors associated with sexual violence.
\end{abstract}

Keywords: Sexual violence, Female, Administrative staff, Mekelle University

\section{Introduction}

As defined by the World Health Organization (WHO) sexual violence is any sexual act, attempt to a sexual act, unwanted sexual comments or advances, or acts to traffic directed against a person's sexuality using force, by any person regardless of their relationship to the victim, and in any setting, such as home and work [1]. Sexual violence is a severe public health problem that has drawn global attention as a worldwide problem [2]. Sexual violence results in short and long-term adverse psychological and social outcomes. In addition, it has significant reproductive health implications such as increased risk for sexually transmitted infections and unwanted pregnancies [1,3]. Though women and girls suffer disproportionately, sexual violence can occur to anybody at any age. It is also an act

*Correspondence: sarabahta21@gmail.com

${ }^{1}$ Ayder Comprehensive Specialized Hospital, Mekelle, Ethiopia

Full list of author information is available at the end of the article of violence that can be perpetrated by parents, caregivers, acquaintances, strangers, and intimate partners [4].

Globally 1 in 3 (35\%) of women have experienced either physical and/or sexual intimate partner violence or non-partner sexual violence in their lifetime [5]. Based on a report from the $\mathrm{WHO}$, the rate of violence against women in African countries was estimated to be $36.3 \%$ [6]. Sexual violence is a widespread problem in sub-Saharan Africa [7]. In Ethiopia, like the other sub-Saharan Africa countries the rate of sexual violence is high which is $59 \%$ of ever-partnered women experienced sexual violence [8]. As part of Ethiopia, in Tigray, sexual violence is still high, for example, a research done in Adigrat hospital shows $60.2 \%$ of rape cases occurred among children and adolescents [9].

Millions faced violence and harassment in workplaces [10]. The potential perpetrators of sexual violence and harassment can be anyone, including employers, workers and third parties (clients, customers, service providers, 
users, patients) [11]. Moreover, victims can be targeted based on different factors such as gender, economic class, race, sexual orientation, disability, or a combination of them factors $[10,11]$. Nevertheless, sexual violence and harassment affect women disproportionately, and men tend to be the perpetrators [11]. Accurately estimating the prevalence of sexual violence in the developing world is difficult because there are few studies done on sexual violence in employed women. Therefore, the aim of this study was to assess factors associated with sexual violence among female administrative staffs of Mekelle University, North Ethiopia.

\section{Main text Methods}

This institution based cross-sectional study was conducted in Mekelle city, North Ethiopia which is $783 \mathrm{~km}$ far from Addis Ababa. Mekelle University has seven campuses, and colleges and all colleges were included in the study. The total number of female administrative staffs working in all campuses were 937. The study population was a sample of the female administrative staff at Mekelle University. The sample size was calculated using single population proportion formula. Using systematic sampling technique, 356 (sample size) females were selected using the Kith value of 3 . Sexual violence was the dependent variable of the study whereas the independent variables were sociodemographic, substance-related, work status and psychosexual characteristics related variables.

Primary data was collected using a structured pretested and self-administered questionnaire that was developed from the existing literature $[12,13]$. The questionnaire was first developed in English then translated to Tigrigna (local language). Before the actual time of data collection, a pre-test was conducted on $10 \%$ similar population in Mekelle city administration not included in the study. Data collectors were assigned to the seven campuses of Mekelle University to distribute and collect the questionnaire. Data entry was conducted using EPI-INFO version 7 computer software, and data cleaning and analysis was done using SPSS version 22. The data cleaning was performed by calculating frequency of each variable to check accuracy, inconsistency and missed the value of the data. Before analysis of the data, recoding of variables was conducted to make it easy for analysis. Descriptive statistics like frequency for normally distributed data and median with interquartile range for non-normally distributed data to all variables were computed. Bivariate logistic regression was used as method of analysis, variables statistically significant with $\mathrm{P}<0.3$ was taken to the multivariable logistic regression. For all statistical significance tests between each independent and dependent variable, significant at $\mathrm{P}<0.05$ was be considered reliable for the analysis of the study.

Sexual violence was operationalized as unwanted sexual act such as a verbal joke, question for sex, faced unwanted kiss, unwelcomed touching of woman's body parts such as breast, genitalia, forced sexual attempt, forced sex without consent/will, forced sex that made a woman frightened and degrading in the past six months.

\section{Results \\ Sociodemographic characteristics}

A total of 356 female administrative staff of Mekelle University participated in this study giving a response rate of $100 \%$. From the total participants, 174 (48.9\%) of them were in the age group 26-35 years, and 171 (48\%) of the participants were married. Regarding ethnicity, majority $(89 \%)$ of them were Tigrians as well as 270 (75.8\%) females were Orthodox Christian. Two hundred thirty-four (65.7\%) participants had educational status of certificate and above. About $22.2 \%$ of the participants were working as runners (transport patients from one department to other department in a hospital). Two hundred and fifteen $(60.4 \%)$ of the participant females had a monthly salary of 500-1500 Birr (Table 1).

\section{Sexual violence}

From the total number of participants, $188(52.8 \%)$ had a shift on their work schedule and $110(30.9 \%)$ of them had day and night shift. About half 180 (50.2\%) of the participants face sexual violence. Similarly, 53 (14.9\%) of the violence was performed by their boss. Workmates and students were also other common perpetrators. The number of female workers who face violence in their workplace was $122(67.8 \%)$ whereas, the rest faced violence was happened outside their workplaces such as in bus and other places. Bullying was the common act of violence as reported by $82(45.5 \%)$ of participants. One hundred fourteen $(63.3 \%)$ of the victims didn't know whether the perpetrators use a substance or not whereas from those who responded yes for substance use, 26 $(57.8 \%)$ of the perpetrators used alcohol. From the total study participants, about $46.4 \%$ had no boyfriend and from those who had boyfriend 105 (29.5\%) of them had regular sexual contact (Table 2).

\section{Factors associated with sexual violence}

To assess the relationship between the dependent and independent variables, logistic regression analysis method was used. In binary logistic regression educational status, workplace, having a night shift, having boyfriend, sexual contact, having multiple partners and knowing other females violated in the office were statistically associated with sexual violence. Whereas, in 
Table 1 Sexual violence vs sociodemographic characteristics of female employees of MU, $2018(n=356)$

\begin{tabular}{|c|c|c|}
\hline \multirow{3}{*}{ Variable } & \multicolumn{2}{|l|}{ Sexual violence } \\
\hline & Yes & No \\
\hline & Freq. Percent & Freq. Percent \\
\hline
\end{tabular}

Age in years$$
\text { 15-25 }
$$

26-35

36-45$$
>45
$$

Marital status

$$
\text { Single }
$$

Married

Divorced

Widowed

Ethnicity

Tigraway

Amhara

Others*

Religion

$$
\text { Orthodox }
$$

Muslim

Others**

Educational status

Primary education (1-8 grade)

Secondary education

Diploma and certificate

Degree and above

Residence

$$
\text { Urban }
$$

Occupation

$$
\text { Secretary }
$$

Receptionist

Runner

Library

Procter

Laundry

Registrar

Others****

Position at work

Office manager

Coordinator

Customer officer

Department head

Others ${ }^{* * *}$

Monthly income in Birr

500-1500

1501-2500

2501-3500

$>3500$

*Afar, Erob; ${ }^{* *}$ Christian: Catholic, Protestant; ${ }^{* * * i m m e d i a t e ~ s u p e r v i s o r s ~}$ of different workplaces; ${ }^{* * *}$ cleaner, guard, administrative works such as accountant, human resource
Table 2 Sexual violence versus different variables among female administrative staffs of MU, $2018(n=356)$

Variable Sexual violence

\begin{tabular}{llll}
\hline Yes & No \\
${$\cline { 1 - 2 }$}$ Percent $}$ & Frequency Percent
\end{tabular}

Shift at work

$\begin{array}{rrrrr}\text { Yes } & 113 & 31.7 & 75 & 21.1 \\ \text { No } & 67 & 18.8 & 101 & 28.4\end{array}$

Program of the shift

$\begin{array}{lrrrr}\text { Day } & 28 & 7.8 & 20 & 5.6 \\ \text { Night } & 23 & 6.5 & 7 & 2.0 \\ \text { Day and night } & 62 & 17.4 & 48 & 13.5\end{array}$

Place where the act performed

$\begin{array}{lrr}\text { In Office } & 122 & 67.8 \\ \text { Street } & 35 & 19.4 \\ \text { Others* }^{*} & 23 & 12.8\end{array}$

How the act was done

Using force $\quad 45 \quad 25$

$\begin{array}{llr}\text { By kicking } & 10 & 5.5\end{array}$

$\begin{array}{lll}\text { Bullying } & 82 & 45.5\end{array}$

Verbal abusing $\quad 43 \quad 23.9$

Did the perpetrator use any substance

$$
\text { Yes } \quad 45 \quad 25 \text {. }
$$

$\begin{array}{lll}\text { No } & 21 & 11.6\end{array}$

I don't know $\quad 114 \quad 63.3$

Type of substance

$\begin{array}{lll}\text { Alcohol } & 26 & 57.8\end{array}$

Khat or others** $^{* *} \quad 19 \quad 42.2$

History of substance violence

$\begin{array}{lrr}\text { Yes } & 101 & 56.1 \\ \text { No } & 10 & 5.6 \\ \text { I don't know } & 69 & 38.3 \\ \text { What type of substance } & \\ \text { Khat chewing } & 45 & 44.5 \\ \text { Smoking } & 20 & 19.8 \\ \text { Alcohol } & 27 & 26.7 \\ \text { Others** }^{*} & 9 & 8.9\end{array}$

Previous history of such practice of the perpetrator

$\begin{array}{lrr}\text { Yes } & 36 & 14.4 \\ \text { No } & 21 & 11.7 \\ \text { I don't know } & 123 & 68.3\end{array}$

Did the perpetrator has more than one partners

$\begin{array}{lll}\text { Yes } & 85 & 47.2 \\ \text { No } & 18 & 10 \\ \text { I don't know } & 77 & 42.8\end{array}$

Do you know the perpetrator well

$\begin{array}{lll}\text { Yes } & 138 & 76.7\end{array}$

$\begin{array}{lll}\text { No } & 42 & 23.3\end{array}$

1.1 28.4 5.6 2.0

7.8

9.4

2.8

5

5.5

3.9

5.

3.3

7.8

6.1

4.4

68.3


Table 2 (continued)

\begin{tabular}{|c|c|c|c|c|}
\hline \multirow[t]{3}{*}{ Variable } & \multicolumn{4}{|c|}{ Sexual violence } \\
\hline & \multicolumn{2}{|l|}{ Yes } & \multicolumn{2}{|l|}{ No } \\
\hline & Frequency & Percent & Frequency & Percent \\
\hline \multicolumn{5}{|c|}{ Did the perpetrator have family } \\
\hline Yes & 95 & 68.8 & & \\
\hline No & 9 & 6.5 & & \\
\hline I don't know & 34 & 24.6 & & \\
\hline \multicolumn{5}{|c|}{ With whom did the perpetrator live } \\
\hline Lonely & 54 & 39.1 & & \\
\hline Family & 45 & 32.6 & & \\
\hline I don't know & 39 & 28.3 & & \\
\hline \multicolumn{5}{|c|}{ How old was the perpetrator } \\
\hline Same as me & 78 & 43.3 & & \\
\hline Older than me & 102 & 56.7 & & \\
\hline \multicolumn{5}{|c|}{ Do you have a boyfriend } \\
\hline Yes & 107 & 30.1 & 58 & 16.3 \\
\hline No & 73 & 20.5 & 118 & 33.1 \\
\hline \multicolumn{5}{|c|}{ If yes how often is your sexual relationship } \\
\hline No sexual contact & 26 & 7.3 & 19 & 5.3 \\
\hline Regular & 66 & 18.5 & 39 & 10.9 \\
\hline \multicolumn{5}{|c|}{ Relationship other than your boyfriend } \\
\hline Yes & 41 & 11.5 & 5 & 1.4 \\
\hline No & 66 & 18.5 & 53 & 14.9 \\
\hline \multicolumn{5}{|l|}{ With how many } \\
\hline One & 18 & 5.1 & 3 & 0.8 \\
\hline Two or more & 23 & 6.5 & 2 & 0.6 \\
\hline \multicolumn{5}{|c|}{ History of sexual violence } \\
\hline One time & 84 & 46.6 & 5 & 2.8 \\
\hline Two times & 24 & 13.3 & 4 & 2.2 \\
\hline Three times & 32 & 17.8 & 0 & 0.0 \\
\hline $\begin{array}{l}\text { More than four } \\
\text { times }\end{array}$ & 30 & 16.7 & 1 & 0.5 \\
\hline \multicolumn{5}{|c|}{ Do you know a woman who is violated in the workplace } \\
\hline Yes & 108 & 30.3 & 48 & 13.5 \\
\hline No & 72 & 20.2 & 128 & 36.0 \\
\hline
\end{tabular}

*Around workplace out of office; **drug, shisha

multiple logistic regression the factors associated with sexual violence were: age, educational status, workplace, having a night shift, having multiple partners and knowing other female violated in office.

Females in the age group 15-25 years were two times at greater risk of sexual violence than the other age groups [AOR: 2.319 (1.059-5.075)]. Similarly, females in high school or lower with their educational status were approximately two times at greater risk of sexual violence as compared to their counterparts [AOR: 1.981 (1.1263.485)]. Type of work was also strongly associated with sexual violence. As a result, females working in office related (secretary, runners) and student-related works (registrar, library, proctor) had 4 and 3 times chance of having sexual violence than the females working in other places (laundry and others) respectively [AOR: 4.143 (1.975-8.687), 2.887 (1.396-5.973)]. The participants who had night shifts were two times at greater risk than those who had not night shifts [AOR: 2.131 (1.2583.611)]. Additionally, females having a history of multiple partners was approximately nine times more at risk of sexual violence as compared to their counterparts [AOR: 8.916 (3.052-26.047)]. Participants who know violence in their workplace were four times risky than those who did not [AOR: 3.920 (2.326-6.606)] (Table 3).

\section{Discussion}

This study aimed to assess sexual violence among female administrative staffs of Mekelle University. The magnitude of sexual violence in the workplace was $34.3 \%$. Whereas in a study done to assess sexual harassment in workplace conducted in Lebanon, the prevalence of sexual violence was $41.9 \%$ [13]. In addition, this finding of the study was lower than a study done in Nepal that asses sexual violence in work place, which showed about $53.8 \%$ of women employees faced sexual violence in their workplace [14]. Similarly, a study done in Malaysia among employed women found that $52.7 \%$ sexual violence was conducted in workplace [15]. This variation might be due to differences in socioeconomic status, study participants, sample size and operational definition of the problem. In this study, for example, any action against the women was considered as sexual violence.

The current study revealed that the common perpetrators of sexual violence were bosses (14.9\%), workmates (12.1\%), students (9.3\%), husbands (7\%) and boyfriends (7.3\%). Whereas, in a study conducted in Nigeria the perpetrators were clients and managers [13]. Similarly, in a study done in Denmark and Danish workplaces sexual violence was conducted by colleagues, supervisors, subordinates [16]. This difference is due to the time gap, study design, and a difference in sociodemographic status.

This study found that females working in studentrelated work such as registrar, proctor and library as well as females working in office related activities were at higher risk of sexual violence as compared to females working in others like laundry [AOR: 4.143 (1.9758.687), 2.887 (1.396-5.973)]. This variation might be due to these areas require much interpersonal interaction that could make them vulnerable to violence. However, in a study done in Denmark and Danish workplaces, participants employed in care work were more often exposed to sexual violence by clients and customers than participants employed in private service, professional work, building and construction, and industrial work [16]. This 
Table 3 Factors associated with sexual violence among the female administrative staff of MU, $2018(n=356)$

\begin{tabular}{|c|c|c|c|c|}
\hline \multirow[t]{2}{*}{ Variable } & \multicolumn{2}{|c|}{ Sexual violence } & \multirow[t]{2}{*}{ COR $(95 \%$ C.I) } & \multirow[t]{2}{*}{ AOR (95\% C.I) } \\
\hline & Yes & No & & \\
\hline \multicolumn{5}{|l|}{ Age in years } \\
\hline $15-25$ & $39(11 \%)$ & $50(14 \%)$ & $0.634(0.379-1.060)$ & $2.319(1.059-5.075)^{*}$ \\
\hline $26-35$ & $96(26.9 \%)$ & 78 (21.9\%) & $0.832(0.464-1.492)$ & $1.773(0.950-3.311)$ \\
\hline$>35$ & $45(16.6)$ & $48(13.5 \%)$ & 1 & 1 \\
\hline \multicolumn{5}{|l|}{ Religion } \\
\hline Christian & $153(43 \%)$ & $161(45.2)$ & $0.528(0.270-1.031)$ & $0.565(0.264-1.210)$ \\
\hline Muslim & $27(7.6 \%)$ & $15(4.2 \%)$ & 1 & 1 \\
\hline \multicolumn{5}{|l|}{ Educational status } \\
\hline Secondary/lower & $72(20.2 \%)$ & $48(13.5 \%)$ & $1.778(1.138-2.777)^{*}$ & $1.981(1.126-3.485)^{*}$ \\
\hline Higher education & 108 (30.3\%) & $128(36 \%)$ & 1 & 1 \\
\hline \multicolumn{5}{|l|}{ Type of work } \\
\hline Office related & $90(25.3 \%)$ & $61(17.1)$ & $0.271(0.147-0.500)^{*}$ & $4.143(1.975-8.687)^{*}$ \\
\hline Student related & 70 (19.7) & 65 (18.2\%) & $0.371(0.200-0.690)^{*}$ & $2.887(1.396-5.973)^{*}$ \\
\hline Others & $20(5.6 \%)$ & $50(14 \%)$ & 1 & 1 \\
\hline \multicolumn{5}{|l|}{ Position at work } \\
\hline Yes & 104 (29.2\%) & 91 (25.6\%) & $1.278(0.841-1.942)$ & $1.288(0.783-2.118)$ \\
\hline No & $76(21.3 \%)$ & 85 (23.9\%) & 1 & 1 \\
\hline \multicolumn{5}{|l|}{ Night shift } \\
\hline Yes & 85 (23.9) & 55 (15.4\%) & $1.968(1.277-3.034)^{*}$ & $2.131(1.258-3.611)^{*}$ \\
\hline No & 95 (26.7\%) & $121(34 \%)$ & 1 & 1 \\
\hline \multicolumn{5}{|l|}{ Boy friend } \\
\hline Yes & 107 (30.1\%) & $58(16.3 \%)$ & $2.982(1.934-4.597)^{*}$ & $1.167(0.549-2.481)$ \\
\hline No & $73(20.5 \%)$ & $118(33.1 \%)$ & 1 & 1 \\
\hline \multicolumn{5}{|l|}{ Sexual contact } \\
\hline Yes & $66(18.5 \%)$ & $39(11 \%)$ & $2.034(1.274-3.245)^{*}$ & $1.103(0.488-2.494)$ \\
\hline No & $114(32 \%)$ & $137(38.5 \%)$ & 1 & 1 \\
\hline \multicolumn{5}{|l|}{ Multiple partner } \\
\hline Yes & $41(11.5 \%)$ & $5(1.4 \%)$ & $10.088(3.882-26.216)^{*}$ & $8.916(3.052-26.047)^{*}$ \\
\hline No & $139(39 \%)$ & $171(48 \%)$ & 1 & 1 \\
\hline \multicolumn{5}{|c|}{ Know violence in the workplace } \\
\hline Yes & $108(30.3 \%)$ & $48(13.5 \%)$ & $4.000(2.561-6.249)^{*}$ & $3.920(2.326-6.606)^{*}$ \\
\hline No & $72(20.2 \%)$ & $128(36 \%)$ & 1 & 1 \\
\hline
\end{tabular}

COR crude odds ratio, $A O R$ adjusted odds ratio, $\mathrm{Cl}$ confidence interval *P $<0.05$

variation might be due to a difference in the study area in which the study done in Denmark, and Danish workplaces were conducted in different areas. In developing countries, casual workers and informal sector workers appear to be particularly subject to harassment [16].

In a study done in Meda-Walabu, the associated factors of sexual violence were chat chewing, history of mother beaten by a partner and having regular boyfriend were positively associated with forced sex [17]. Additionally, A cross-sectional study in Iran showed that drugs used in their husbands were associated with sexual violence [18]. However, in this study substance use by the perpetrator and having boyfriend were not statistically associated with sexual violence. The variation in different studies is because this study was done in the workplace in which substance use is not allowed during working hours. Whereas the other studies were done in schools and the public.

In this study, the participants who had night shifts were two times at greater risk than those who had not night shifts [AOR: 2.131(1.258-3.611)]. This difference is because night time is a more convenient for violent people. Additionally, females having a history of multiple partners were approximately nine times more at risk of sexual violence as compared to their counterparts [AOR: 8.916 (3.052-26.047)]. Because in such situation 
disagreements can be apparent that leading to sexual/ physical violence. However, it was difficult to compare these findings with other studies because there is no existing literature on this issue.

\section{Conclusion}

This study found that sexual violence was committed against half of the female administrative staffs of Mekelle University. The typical perpetrators were bosses and workmates, and the common areas of violence were workplaces. The factors associated with sexual violence in this study were, younger age, high school and lower in educational status, office and students related workplace, having a night shift, having multiple partners and knowing other female violated in office.

\section{Limitations of the study}

- Qualitative study is not included in the which was ideal to assess additional factors associated with sexual violence.

- Lack of published papers on sexual violence which make this study to compare with other studies.

\section{Abbreviations}

AOR: adjusted odds ratio; $\mathrm{Cl}$ : confidence interval; $\mathrm{COR}$ : crude odds ratio; WHO: World Health Organization.

\begin{abstract}
Acknowledgements
My deepest gratitude goes to school of nursing, college of health science, Mekelle University for giving me this chance as well as to Ayder comprehensive specialized hospital for sponsoring me. I would like to say thank you to all Mekelle university, school of nursing staffs for their support. Finally, I want to thank the study participants, Mekelle University administrative bodies, my families and all those who support me from the beginning up to the end of this study. It is because of you all, this study becomes evident.
\end{abstract}

\section{Authors' contributions}

SBG, HBG and YTA made substantial contributions to conception and design, or acquisition of data, or analysis and interpretation of data. KGG, AFA, KGH and GBA have been involved in drafting the manuscript or revising it critically for important intellectual content. All authors agreed to be accountable for all aspects of the work in ensuring that questions related to the accuracy or integrity of any part of the work are appropriately investigated and resolved. All authors read and approved the final manuscript.

\section{Funding information}

There was no funding source for this study

\section{Availability of data and materials}

The datasets used and/or analyzed during the current study available from the corresponding author on reasonable request

\section{Ethics approval and consent to participate}

Ethical approval was secured from institutional review board of Mekelle University College of health science. After the permission received from $\mathrm{MU}$, the colleges informed using formal letter. Written informed consent was obtained and respondents was notified the right to refuse or terminate at any point of the filling the questionnaire. The information provided by each respondent kept confidential and no personal identifiers were used.

\section{Consent for publication}

Not applicable.

\section{Competing interests}

The authors declare that they have no competing interests.

\section{Author details}

${ }^{1}$ Ayder Comprehensive Specialized Hospital, Mekelle, Ethiopia. ${ }^{2}$ College of Health Science, School of Nursing, Mekelle University, Mekelle, Ethiopia. ${ }^{3} \mathrm{Dr}$ Tewelde Legesse Health Science College, Mekelle, Ethiopia.

Received: 4 June 2019 Accepted: 14 December 2019

Published online: 07 January 2020

References

1. Kouta C, Pithara C, Zobnina A, Apostolidou Z, Christodoulou J, Papadakaki $M$, et al. A systematic review of training interventions addressing sexual violence against marginalized at-risk groups of women. Health Educ Res. 2015;30(6):971-84.

2. Babaei N, Rahmani A, Avazeh M, Mohajjelaghdam AR, Zamanzadeh V, Dadashzadeh A. Determine and compare the viewpoints of nurses, patients and their relatives to workplace violence against nurses. J Nurs Manag. 2018;26(5):563-70.

3. Jordan CE, Campbell R, Follingstad D. Violence and women's mental health: the impact of physical, sexual, and psychological aggression. Annu Rev Clin Psychol. 2010;6:607-28.

4. Advancement of women: ICRC statement to the United Nations, 2016; 2016.

5. WHO. Violence against women:WHO; 2017. http://www.who.int/media centre/factsheets/fs239/en/.

6. Nasrabadi AN, Abbasi NH, Mehrdad N. The prevalence of violence against Iranian women and its related factors. Global J Health Sci. 2015;7(3):37.

7. WHO. Global and regional estimates of violence against women: prevalence and health effects of intimate partner violence and non-partner sexual violence; 2013.

8. Garcia-Moreno C, Jansen HA, Ellsberg M, Heise L, Watts CH. Prevalence of intimate partner violence: findings from the WHO multicountry study on women's health and domestic violence. Lancet. 2006;368(9543):1260-9.

9. Gessessew A, Mesfin M. Rape and related helath problems in Adigrat Zonal Hospital, Tigray Region, Ethiopia. Ethiopian J Health Dev. 2004;18(3):140-4.

10. Henry C, Adams J. Spotlight on sexual violence and harassment in commercial agriculture lower and middle income countries. Geneva: International Labour Organization; 2018.

11. ILO. Ending violence and harassment against women and men in the world of work. Geneva: International Labour Organization; 2018.

12. Tiruneh BT, Bifftu BB, Tumebo AA, Kelkay MM, Anlay DZ, Dachew BA. Prevalence of workplace violence in Northwest Ethiopia: a multivariate analysis. BMC Nurs. 2016;15(1):42.

13. Hejase HJ. Sexual harassment in the workplace: an exploratory study from Lebanon. J Manag Res. 2015;7(1):107-21.

14. Rahama MR, Jahan N. Sexual harassment in workplace in South Asia: a comparative study on Bangladesh, India, Nepal and Srilanka. IOSR J Bus Manag. 2015;17(6):49-57.

15. Hutagalung F, Ishak Z. Sexual harassment: a predictor to job satisfaction and work stress among women employees. Procedia-Soc Behav Sci. 2012;65:723-30.

16. Friborg MK, Hansen JV, Aldrich PT, Folker AP, Kjær S, Nielsen MBD, et al. Workplace sexual harassment and depressive symptoms: a cross-sectional multilevel analysis comparing harassment from clients or customers to harassment from other employees amongst 7603 Danish employees from 1041 organizations. BMC Public Health. 2017;17(1):675 
17. Bekele T, Kaso M, Gebremariam A, Deressa W. Sexual violence and associated factors among female students of Madawalabu University in Ethiopia. Epidemiology. 2015;5(190):2161.

18. Song Y, Ji C-Y, Agardh A. Sexual coercion and health-risk behaviors among urban Chinese high school students. Global Health Action. 2014;7(1):24418

\section{Publisher's Note}

Springer Nature remains neutral with regard to jurisdictional claims in published maps and institutional affiliations.
Ready to submit your research? Choose BMC and benefit from:

- fast, convenient online submission

- thorough peer review by experienced researchers in your field

- rapid publication on acceptance

- support for research data, including large and complex data types

- gold Open Access which fosters wider collaboration and increased citations

- maximum visibility for your research: over 100M website views per year

At BMC, research is always in progress.

Learn more biomedcentral.com/submissions 